\title{
Capillariaisis (Trichurida, Trichinellidae, Capillaria hepatica) in the Brazilian Amazon: low pathogenicity, low infectivity and a novel mode of transmission
}

Luis Marcelo Aranha Camargo ${ }^{1,2^{*}}$, Juliana de Souza Almeida Aranha Camargo ${ }^{2}$, Luana Janaina de Souza Vera ${ }^{2}$, Pedro di Tarique Crispim Barreto ${ }^{3}$, Eudes Kang Tourinho ${ }^{4}$, Marcia Maria de Souza ${ }^{5}$

\begin{abstract}
Background: Human capillariasis caused by Capillaria hepatica (syn. Calodium hepaticum) is a rare disease with no more than 40 cases registered around the world. Classically, the disease has severe symptoms that mimic acute hepatitis. Natural reservoirs of C. hepatica are urban rodents (Mus musculus and Rattus novergicus) that harbor their eggs in the liver. After examining the feces of 6 riverine inhabitants (Rio Preto area, $8^{\circ} 03^{\prime} \mathrm{S}$ and $62^{\circ} 53^{\prime} \mathrm{W}$ to $8^{\circ} 14^{\prime} \mathrm{S}$ and $62^{\circ} 52^{\prime} \mathrm{W}$ ) of the State of Rondonia, Brazil, and identifying C. hepatica eggs in their feces, the authors decided to investigate the real dimension of these findings by looking for two positive signals.
\end{abstract}

Methods: Between June $1^{\text {st }}$ and $15^{\text {th }}, 2008,246$ out of 304 individuals were clinically examined. Blood samples were collected, kept under $-20^{\circ} \mathrm{C}$, and test by the indirect immunofluorescence technique.

Results: The first positive signal was the presence of specific antibodies at 1:150 dilution, which indicates that the person is likely to have been exposed to eggs, most likely non-infective eggs, passing through the food chain or via contaminated food (total prevalence of 34.1\%). A second more specific signal was the presence of antibodies at higher titers, thus indicating true infection.

Conclusions: The authors concluded that only two subjects were really infected (prevalence of $0.81 \%$ ); the rest was false-positives that were sensitized after consuming non-embryonated eggs. The present study is the first one carried out in a native Amazonian population and indicates the presence of antibodies against $C$. hepatica in this population. The results further suggest that the transmission of the parasite occurs by the ingestion of embryonated eggs from human feces and/or carcasses of wild animals. The authors propose a novel mode of transmission, describing the disease as a low pathogenic one, and showing low infectivity.

\section{Background}

Capillariasis is a cosmopolitan helminthiasis with zoonotic characteristics. Its etiological agent infects many species of mammals, birds, fish and invertebrate animals [1-10]. The etiological agents belong to the phylum Nematoda, order Trichurida, family Trichinellidae and genus Capillaria. This genus contains 300 species of which three are well known human parasites, namely: Capillaria philippinensis, C. aerophila and C. hepatica,

\footnotetext{
* Correspondence: spider@icb5usp.med.br

'Department of Parasitology, University of Sao Paulo, Sao Paulo, Brazil
}

which infect the bowels, the lower breathing airways and the liver, respectively [11].

Traditionally, most authors consider liver capillariasis a rare disease. Among at least 40 cases of parasitism caused by $C$. hepatica that have been registered in the literature, five occurred in Brazil [12,13]. Moreover, eggs of $C$. hepatica have been identified in the feces of individuals of Brazilian indigenous populations $[14,15]$.

Eggs can be ingested from the soil or from carcasses of dead animals. Animal models have shown that the larvae of $C$. hepatica hatch at the level of the cecum, penetrate the mucous membrane and reach the porta 
system until they lodge in the hepatic parenchyma. Finally, after 1 month, they become adult worms. Fertilized eggs spread in groups around the females, which die within thirty days. The eggs remain viable and immature for approximately 120 days. In order for embryogenesis to occur, the eggs must reach the environment, which in this case is possible only after the death of the infected host and disintegration of its carcass. Alternatively, ingestion of organs (eg., liver) containing non-embryonated eggs and their further elimination through the feces, will also induce embryogenesis, thus resulting in infective eggs in the soil [16,17].

Clinical manifestations are related to the inflammatory reaction it causes in the adjacent tissues. Because they affect the hepatic tissue, clinical forms similar to those of acute viral hepatitis and the classical triad (fever, hepatomegaly and eosinophilia) may be present [18]. After diagnosing 6 riverine inhabitants of the State of Rondonia, Brazil, eliminating eggs of $C$. hepatica in their feces, the authors decided to investigate the real dimension of these findings by looking for positive signals at two levels. The first positive signal was the presence of specific antibodies at the $1 / 150$ dilution, which indicates that the person is likely to have been exposed to eggs, most likely non-infective eggs, passing through the food chain or via contaminated food. A second more specific signal was the presence of antibodies at higher titers, thus indicating true infection.

\section{Methods}

\section{Study Area}

This work was performed in the locality of the Preto River, at the intersection of Machado River with Madeira River, Rondonia State, western Brazilian Amazon.

The study area $\left(8^{\circ} 03^{\prime} \mathrm{S}\right.$ and $62^{\circ} 53^{\prime} \mathrm{W}$ to $8^{\circ} 14^{\prime} \mathrm{S}$ and $\left.62^{\circ} 52^{\prime} \mathrm{W}\right)$ is inhabited by 304 individuals. These people are descendants of the "rubber soldiers" of the XIX and $\mathrm{XX}$ centuries, of native populations, and from immigrants from the south and southwestern regions of the country. This area lacks electricity and medical care. Houses are made of wood with thatched or asbestos roofs (Fig. 1). There are no toilets and excrements are thrown around the houses or dumped in cesspits located 10 to 20 meters from the houses. Water is taken from the river or from small wells known as "cacimbas" and it is consumed unfiltered and without any treatment. People earn their living working the land for their subsistence, selling the excess product to bargaining small merchants. Some people sell the pulp of native fruits (cacao, cupuassu, etc.) in Porto Velho, located more than $250 \mathrm{~km}$ away. The basic diet is fish, manioc flour, seasonal fruits and wild animals, such as monkeys,

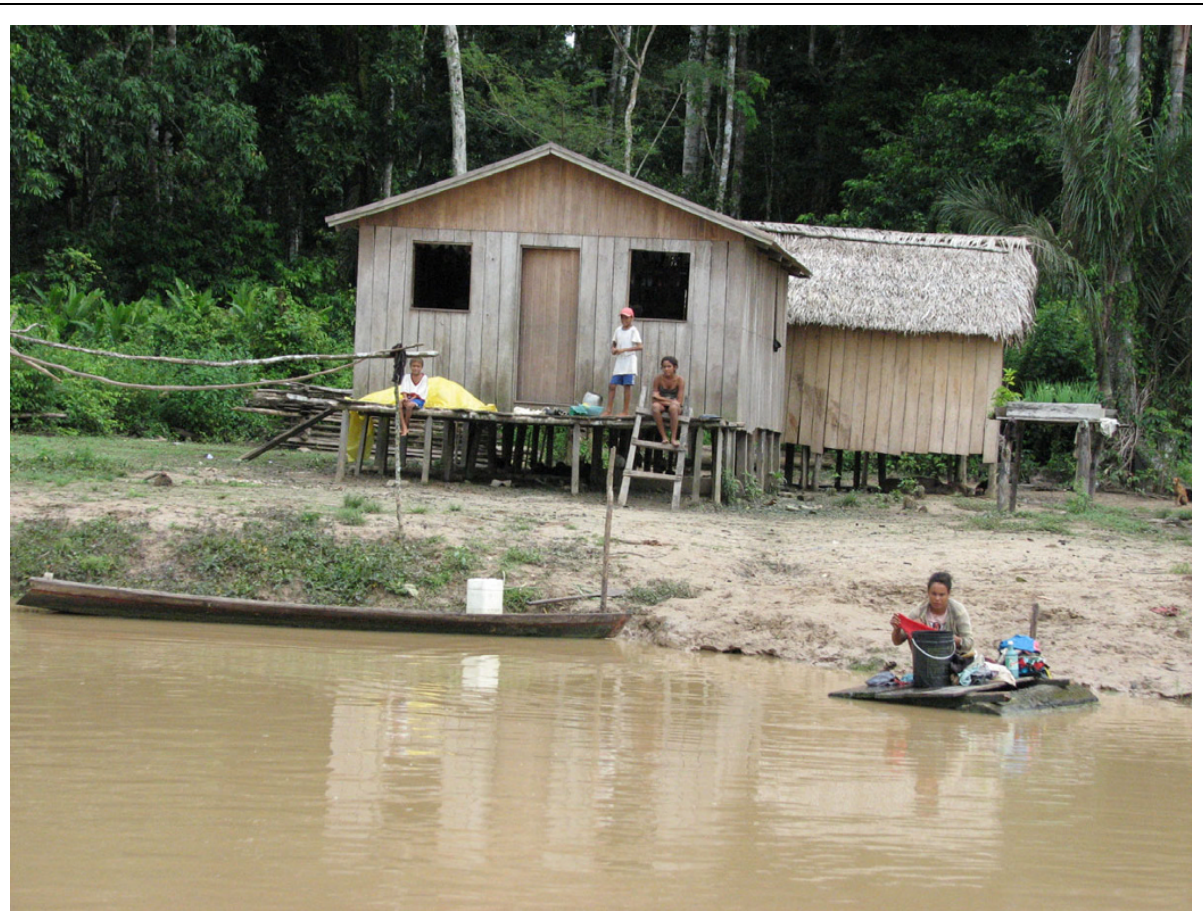

Figure 1 Typical house and riverine inhabitants along the Rio Preto river, Rondonia, Amazon region, Brazil. 
peccaries (Tayassu spp.), paca (Agouti paca), cotia (Dasyprocta aguti), deer, alligators, birds, etc.

\section{Population Data Collection}

In the past 6 years, researchers from the University of São Paulo have been studying the Preto River area, registering its population. During this period the researchers diagnosed 6 inhabitants who presented C. hepatica eggs in their feces. Because the community is very small, all individuals were examined by the medical staff, except those who were not present in the community between June $1^{\text {st }}$ and $15^{\text {th }}, 2008$. From the 304 permanent inhabitants, 246 were present at the time of the study and all were examined.

\section{Collection and processing of biological samples}

Subjects read and signed a term of consent prior to the collection of samples. A volume of $10 \mathrm{~mL}$ of blood was collected from each subject in dry tubes by venous puncture, after the due asepsis of the forearm. Blood samples were kept at room temperature for 3 to 4 hours and then centrifuged at 3,000 rpm for 10 minutes. Each serum sample was kept at $-20^{\circ} \mathrm{C}$, until the serological exam was carried out.

Serum samples were diluted in saline buffered solution (PBS) at $50 \%$ to $1 / 150$ and tested against paraffin cuts containing mice livers with $C$. hepatica eggs and worms, according to the technique proposed previously [19]. The same author suggests a cut-off of $1 / 400$ to diagnose false from- true-positive cases. False-positive cases occur after the ingestion and immunological sensibilization by nonembryonated eggs. On the other hand, true-positive cases are the ones that ingested embryonated eggs and harbor the worms in the liver tissue. Results proved to be positive ( $>1 / 150)$ were scored as weak (PI), median (PII) and strong (PIII), based on fluorescence intensity, according to personal criteria of two different examiners. Nine of the 13 serum samples with median or strong reactions were further diluted to 1:500 and 1:1000 (higher than the cut-off level) in PBS and re-tested, in an attempt to exclude cases with unspecific fluorescence as suggested by Assis [19] The same technique was tested by JunkerVoss [20], who demonstrated a high specificity and sensibility to $C$. hepatica, with no cross-reactivity for serum samples of patients with documented infections of Echinococcus granulosus, E. multilocularis, Fasciola. hepatica, Schistosoma mansoni, Toxocara canis, Trichuris trichiura, and Trichinella spiralis.

Complementary laboratory tests (haemogram, AST/ ALT, Billirubin, Gamma-glutamyltransferase, platelets count, B and C hepatitis serology, cytomegalovirus serology, feces parasitological exams) and ultrasonographic examination of the liver aiming to find alterations that could characterize hepatic capillariasis were performed for all the serological positive patients at the same time and using the same biological samples.

\section{Statistical Analyses}

Information was stored in an Excell $^{\circledR}$ data file and analyzed by Epi Info 6.2. Qualitative variables (sex, age groups, positive/negative test and place of origin) were analyzed using the chi-square test and multivariate logistic regression. Quantitative variables (time living in the Amazon and in the study area, family income and age) were analyzed through the nonparametric MannWhitney U test, since these variables showed a non-normal distribution for the Shapiro-Wilk test. The significance level was set at 0.05 .

\section{Ethical approval}

This study was submitted to the Ethics Committee of the São Lucas School, registered under number PT/ $\mathrm{CEP} / 10 / 08$.

\section{Results}

A total of 246 subjects (81\%) out of the 304 permanent inhabitants of the community had their serum samples examined. The population was basically composed by 194 native individuals $(79 \%)$ and $52(21 \%)$ people currently living in the area but original from outside the Amazon (immigrants). 41\% reported to earn their living from agriculture and fishing, $28 \%$ performed activities related to home care and $28 \%$ were students. The rest of the population was composed of civil servants and small dealers. When examined, 10 individuals (4\%) presented positive haemoscopy for malaria (Plasmodium vivax and P. falciparum).

Over ninety percent (91.7\%) of the people interviewed informed they had eaten paca and/or agouti, and/or peccary meat within the previous 15 days, suggesting that this is a frequent habit in this population.

In order to verify if the remaining inhabitants of the community $(19 \%)$ that were not sampled in the present study had a different profile from the sampled group tested by serology, we performed a statistical analysis (qui-square test, multivariate logistic regression and Mann-Whitney U test) of certain variables (sex, age, place of origin, time of residence in Rondonia and in the study area) and no significant statistical differences was found, thus suggesting that the sampled population is representative of our findings.

Of the total number of subjects, 84 showed weak, median, or strong positive serology at the 1/150 dilution, representing a total prevalence of $34.1 \%$. Subjects who showed weak positive serology were in greater proportion than patients in the other two categories $\left(\mathrm{x}^{2}=\right.$ 101.2, $\mathrm{p}<0.0001$ ). 
There was no statistic significance between seropositivity among the three age groups: 0 to 15 years (children group), 16-60 years (young group), and $>60$ (elderly group) ( $\mathrm{x}^{2}$ Yates corrected $=0.48,2$ df., $\left.\mathrm{p}=0.7867\right)$. Additionally, no significance was detected among the two sexs $\left(x^{2}\right.$ Yates corrected $\left.=2.34, d f=2, p=0.1277\right)$.

However, when the place of origin (Amazon or outside Amazon) was compared by the qui-square test, those original from the Amazon region presented significantly more soropositivity (79/194 inhabitants, 40.7\%) when compared to inhabitants original from outside the Amazon (5/52 soropositive, 9.6\%) $\left(\mathrm{x}^{2}=17,65, \mathrm{p}<0.0001\right)$.

After controlling the covariates, the only significant factor related to capillariasis was the individual's place of origin (from Amazon) (odds ratio 3.9219, CI 95\%, 1.1089-13.8702). In other words, Amazonians have 4 times more chance of developing capillariasis then those born elsewhere. No significant association was found between capillariasis and age or sex. (Table 1).

Of the 13 positive cases classified as median or strong, nine samples were re-examined at 1: 500 and 1:1000 dilutions. Maintenance of immunofluorescence at these dilutions is considered to be specific for Capillaria hepatica [19]. Of these, only 2 sera (one 4 years-old boy and one 34 years-old woman) remained positive after the dilution to $50 \%$ with PBS, thus characterizing a strong seroprevalence of only $0.81 \%$ among the sampled population. All nine patients were subjected to complementary laboratory tests (haemogram, AST/ALT, bilirrubin, gamma-glutamyltransferase, platelets count, $B$ and $C$ hepatitis serology, cytomegalovirus serology, and feces parasitological exams) and ultrasonographic examination of the liver aiming to find alterations that could characterize hepatic capillariasis. All results were normal for the nine patients.

\section{Discussion}

The target population is young (averaging 26 years) and has been living in Rondonia for 21 years, 14.8 of those

\begin{tabular}{|c|c|c|c|c|}
\hline Variables & $\begin{array}{c}\text { Odds Ratio (IC } \\
95 \%)\end{array}$ & $\beta_{i}$ & $\begin{array}{l}\text { Standard } \\
\text { Error }\end{array}$ & $\begin{array}{c}\mathrm{P}- \\
\text { Value }\end{array}$ \\
\hline $\begin{array}{l}\text { Amazon } \\
\text { origin }\end{array}$ & $\begin{array}{c}3,9219 \\
(1,1089-13,8702)\end{array}$ & 1,3666 & 0,6445 & 0,0340 \\
\hline Sex & $\begin{array}{c}1,4609 \\
(0,8526-2,5030)\end{array}$ & 0,3790 & 0,2747 & 0,1677 \\
\hline $\begin{array}{l}\text { Age Group } \\
(16-60)\end{array}$ & $\begin{array}{c}1,3882 \\
(0,7950-2,4238)\end{array}$ & 0,3280 & 0,2844 & 0,2488 \\
\hline $\begin{array}{l}\text { Age Group } \\
(>60)\end{array}$ & $\begin{array}{c}1,9175 \\
(0,5728-6,4193)\end{array}$ & 0,6510 & 0,6165 & 0,2910 \\
\hline Intercept & \# & $-0,1658$ & 0,2560 & 0,5171 \\
\hline
\end{tabular}

years in the Rio Preto area. Most of the population is composed of native individuals (79\%), fishermen, or people engaged in subsistence agriculture (41\%) with a malaria prevalence of $4 \%$. The technique used here is highly specific for $C$. hepatica and the findings confirmed the presence of antibodies against this nematode in the western Brazilian Amazon, thus indicating the occurrence of infection among the sampled population. Nevertheless, in spite of its dispersion, this parasitic disease seldom seems to induce illness, since none of the patients analyzed showed symptoms of hepatic capillariasis. However, when subjects become ill [13,21-25], disease evolution is generally serious [26].

The prevalence found in the target population of this study $(34.1 \%)$, independently of its reactivity (weak, median or strong), is roughly similar to the $44.2 \%$ value reported by Galvão [27] when he studied 500 lowincome children in Salvador, Bahia, northeastern Brazil. Galvão [27] associated the high prevalence observed with some factors such as the low socio-economic level of the population and the possibility of rat carcasses exposing embryonated eggs in the environment, thus causing contamination [27]. However, our results show that after diluting the sera, the prevalence value dropped to $0.81 \%$, thus suggesting that the occurrence of falsepositive cases is significant when the dilution of $1 / 150$ is used. The same phenomenon was observed by Galvão [27], who reported a drop in prevalence to $1.8 \%$ after diluting the positive sera to $1 / 500$.

In another study with samples from 60 workers of the Vienna Zoo, Juncker-Voss [20] found a serum prevalence of $3.3 \%$ in sera diluted $1 / 40$ using the indirect immunofluorescence technique. All serum positive workers were asymptomatic, with no hepatic enzyme alterations, and remained so until the conclusion of the study. After two months, serology was repeated and the test remained positive in only one of the patients. In order to test the accuracy of the diagnostic tool, patients' sera were further tested by ELISA and by the indirect immunofluorescence technique with antigens against Echinococus granulosus, E. multioculares, Toxocara canis, Schistosoma mansoni, Fasciola hepatica, Trichuris trichiura and Trichinella spiralis, showing no positive reactions and suggesting a high specificity of this test for $C$. hepatica. The authors suggest that the infections by $C$. hepatica originated from carcasses of Mus musculus, which were abundant in the zoo.

An experimental study with Wistar rats [19] confirmed the excellent sensitivity and specificity of the indirect immunofluorescense technique and estimated that positivity starts 15 days after infection and lasts for three months. In false-positive cases (ingestion of nonembryonated eggs) reactions are initially positive; however, dilutions equal or greater than $1 / 400$ show a 
negative reaction. Moreover, infections with over 3 months of duration show negative reactions, thus suggesting a fall in antibody level as the eggs are destroyed in the hepatic tissue.

Considering these previous studies and in view of the high serum prevalence $(34.1 \%)$ found at the initial dilution of $1 / 150$ in the present study, we may conclude that this riverine population is in great contact with non-embryonated and embryonated eggs of $C$. hepatica, When positive sera were further diluted to equal or greater than $1 / 500$, the prevalence falls to $0.81 \%$ (two patients). All patients with medium or high serology reactions, when first examined, did not present clinical symptoms nor liver alterations at the biochemical or ultrasonographic levels, thus characterizing a parasite of low pathogenicity, as many authors have proposed [13,21-25]. On the other hand, it is probable that there is a low environmental contamination with embryonated eggs, due to the high dispersion of people in this area, which could lead to infections with a low quantity of eggs and a consequent benign evolution of the disease. It must be considered that many authors have registered the contrast between the abundance of $C$. hepatica eggs in the environment and the rare occurrence of clinical cases of the disease [28-31]. These findings corroborate the low prevalence of carriers for the nematode $C$. hepatica.

Nevertheless, we must consider that since the present study focused on prevalence and since the antibodies do not remain in the blood for over 3 months [19], timely antibody detection is required. Thus, it is possible that the exposure to $C$. hepatica could have been underestimated in the sampled population.

The similarity of the serum prevalence distribution according to sex and among the three age groups indicates that the risk of exposure is equivalent among the population. This result contrasts with Galvão [27], who reported that the highest infection risk was among children, who were supposedly more exposed to eggs and rats' carcasses.

Another interesting finding is the greater serum prevalence in individuals original from the Amazon region, when compared to those original from outside the Amazon. This higher prevalence in Amazonian individuals may suggest that cultural habits (eating wild animal viscera) non-existent or less practiced by non-Amazonians is a factor to be considered in the infectivity of C. hepatica. However, the overall high serum prevalence found in the sampled population may be explained by the relatively few people from outside the Amazon that live in the region.

Contrary to the hypothesis formulated by Galvão [27], who proposed that people are contaminated by embryonated eggs from carcasses of urban rodents (which do not exist in the Amazon rain forest), we hypothesize that the riverine population under study can be exposed to the parasite's eggs by two non-exclusive mechanisms:

a-) ingestion of non-embryonated eggs from giblets of paca (Agouti paca)[2], peccaries (Tayassu spp.), agouti (Dasyprocta aguti), monkeys and other wild animals [16]. The consumption of giblet "farofa" (dish made of manioc flour browned in oil, mixed with giblets of these animals) is very common among these populations. These individuals may ingest livers contaminated with non-embryonated eggs and then act as carriers, disseminating $C$. hepatica eggs in the stool. This hypothesis is reinforced by the fact that $91.7 \%$ of the interviewed patients affirmed that they had eaten paca, agouti or peccary meat within the fifteen days prior to the interview.

b-) ingestion of environmental embryonated eggs from water or food contaminated with feces of individuals that had consumed contaminated viscera (false-positive) or with eggs from the carcasses of animals. This mechanism would be facilitated by the fact that there are no adequate methods of disposal of human excrements in the area.

These transmission routes may be investigated in the future by examining the subject's feces and investigating whether there is contamination of the soil with $C$. hepatica eggs.

Due to its particularities, our study area contrasts to other areas previously studied. Galvão [27] and JunkerVoss [20] suggested that the rodent Mus musculus seemed to play an important role in the transmission in their study areas. In the riverine population studied here, M. musculus is absent and there is no human agglomeration. Therefore, low transmission, low parasitary load and, consequently, low pathogenicity are observed.

\section{Conclusions}

This study describes for the first time the occurrence of infection by $C$. hepatica in the Brazilian Amazon. Cultural aspects such as the diet (which includes viscera of wild animals) and the total lack of sanitation suggest in the future a somber perspective of inadequate control for the dissemination of the disease. Although C. hepatica showed a low level of pathogenicity and disease onset in this study, capillariaisis is severe enough to be considered a different pathology from the numerous other regional diseases that can cause fever and hepatosplenomegaly, such as malaria, trichinellosis, toxocariasis, arbovirosis, hepatitis, hepatic tumors, thyphoid fever and other helmintosis. Basic sanitation (septic tanks), together with educational orientation related to hygiene and food preparation (cooking food and avoiding the ingestion of viscera) may help to control this endemic 
disease. Complementary studies must be made in order to identify other wild carriers of $C$. hepatica among wild animals, in the region such as monkeys, deers, and wild rodents.

\section{Acknowledgements}

We would like to thank Prof Marisis Camargo and Dr Johana R. Perez (UNICAMP) for the English review of this manuscript, Prof Marcelo Bahia Labruna (University of São Paulo) for the critical review of the article, Prof Zilton de Andrade for facilities to realize the IFI, the Brazilian National Research Council (budget No. 470510/2006-4) and the people from the Rio Preto community for their collaboration.

\section{Author details}

'Department of Parasitology, University of Sao Paulo, Sao Paulo, Brazil. ${ }^{2}$ Department of Medicine, São Lucas Faculty, Rondonia, Brazil. ${ }^{3}$ University of Rondonia, Rondonia, Brazil. ${ }^{4} 9$ de Julho Hospital, Rondonia, Brazil. ${ }^{5}$ Oswaldo Cruz Foundation, Bahia, Brazil.

\section{Authors' contributions}

LMAC: elaboration and review of the manuscript and physical examination of the patients. JSAAC: elaboration of the manuscript and laboratory tests. LVVS: elaboration of the manuscript and laboratory tests. PTC: elaboration, review of the manuscript and statistical analysis. EKT: elaboration and review of the manuscript and ultrasonographic examination. MMS: elaboration and review of the manuscript and immunofluorescence test.

\section{Competing interests}

The authors declare that they have no competing interests.

Received: 1 December 2009 Accepted: 26 February 2010 Published: 26 February 2010

\section{References}

1. Mandorino L, Rebouças MM: Hepatic capliariasis in catitu (Tayassu tajacu). Ara Inst Biol São Paulo 1991, 58:61-62.

2. Matamoros $Y$, Velazquez M, Pashov B: Parasitos intestinales del tepezcuinte Agouti paca (Rodentia: Dasyproctidae) em Costa Rica. Rev Biol Trop 1991, 39:173-176.

3. Claveria FG, Causapin J, De Guzman MA, Toledo MG, Salibay C: Parasite biodiversity in Rattus spp caught in wet markets. Southeast. Asian J Trop Med Public Health 2005, 36(Suppl I):146-8.

4. Nakamura N: Parasitic lesions of bovine liver attributed to capillaria species. J Comp Pathology 2005, 132:228-31.

5. Paramasvaran S, Krishnasamy M, Lee LH, Jeffrey J, Hakin L, Malik NB, Sani RA, Santhana RL: Helminth infections in small mammals from Ulu Gombak Forest Reserve and the risk to human health. Tropical Biomedicine 2005, 22:191-194.

6. Fiorello CV, Robbins RG, Maffei L, Wade SE: Parasites of free-raging small canids and felids in the Bolivian Chaco. J Zoo Wildl Med 2006, 37:130-4.

7. Fugassa MH, Denegri GM, Sardella NH, Araujo A, Guichon RA, Martinez PA, Civalero MT, Aschero C: Paleoparasitological records in a canid coprolite from Patagônia, Argentina. J Parasitol 2006, 92:1110-3.

8. Timi JT, Rossin MA, Lanfranchi AL: A new species of Capillaria (Nematoda: Capillariidae) parasitizing Conger orbignianus (Pisces Congredae) from Argentina. J Parasitology 2006, 92:628-30.

9. Easterbrook JD, Kaplan JB, Vanasco NB, Reeves WK, Purcell RH, Kosov MY, Glass GE, Watson J, Klein SL: A survey of zoonotic pathogens carried by Norway rats in Baltimore, Maryland USA Epidemiology. Infect 2007, 15:1-8.

10. Tietz Marques SM, Marinho De Cuadros R, Jardim Da Silva C, Baldo M: Parasites of pigeons (Columba livia) in urban areas of lages, Southern Brazil. Parasitol Latinoam 2007, 62:183-187.

11. Okulewicz A, Zalensny G, Zaklad M: Biodiversity of nematode fauna. Parazytologii, Instytut Genetyki I Mikrobiologii, Uniwersystet Worclaski, Wiad. Parazyto 2005, 51:9-14.

12. Piazza $R$, Correa MO, Fleury RN: On case of human infestation with Capillaria hepatica. Rev Inst Med Trop São Paulo 1963, 5:37-41.
13. Sawamura R, Fernandes MIM, Peres LC, Galvão LC, Goldani HAS, Jorge SM, Rocha G, Souza NM: Hepatic Capillariasis in Children: Report of 3 cases in Brazil. Am J Trop Med Hyg 1999, 61:642-647.

14. Coimbra CE Jr, Melo DA: Enteroparasites and Capillaria sp. among the Surui tribe, Parque Indigena Aripuana, Rondonia. Mem Inst Oswaldo Cruz 1981, 76:299-302.

15. Santos RV, Coimbra JRCEA, OTT AMT: Estudos epidemiológicos entre grupos indígenas de Rondonia III: Parasitoses intestinais nas populações dos vales dos rios Guaporé e Mamoré. Cad Saúde Pública 1985, 1:467-477.

16. Collier L, Balows A, Sussman M: Strongyloides and Capillaria. Toplye's Microbiology and Microbial Infections New York: Oxford University PressTopley, Wilson, 9 1998, V:585-595.

17. Lee CW: The experimental studies on Capillaria hepatica. Kisaengchunhak Chapochi 1964, 2:63-80.

18. Choe G, Lee HS, Seo JK, Chai JY, Lee SH, EOM KS, Chi JG: Hepatic capillariasis: first case report in the Republic of Korea. Am J Trop Med Hyg 1993, 48:610-25.

19. Assis BC, Cunha LM, Baptista AP, Andrade ZA: A contribution to the diagnosis of Capillaria hepatica infection by indirect immunofluorescence test. Mem Inst Oswaldo Cruz 2004, 99:173-7.

20. Juncker-Voss M, Prost H, Lussy H, Ezenberg U, Auer H, Lassnig H, Muller M, Nowotny N: Screening for antibodies against zoonotic agents among employees of the Zoologica Garden of Vienna, Schönbrunn, Austria. Berl Munch Tierarztl Wochenschr 2004, 117:404-9.

21. Berger T, Egremont A, Gobbers JO, Tönz E: Hepatic capillariasis in a 1year-old child. Eur J Pediatr 1990, 149:333-336.

22. Cochrane JC, Sagorin L, Wilcocks MG: Capillaria hepatica infection in man; a syndrome of extreme eosinophilia, hepatomegaly and hyperglobulinaemia. S Afr Med J 1957, 27:751-5.

23. Otto GF, Berthon M, Appleby RE, Rawlins JC, Wilbur O: Eosinophilia and hepatomegaly due to Capillaria hepatica infection. Bull Johns Hopkins Hosp 1954, 94:319-36.

24. Vargas CG, López MH, Victoria R, Hernandez MG: Capillaria hepatica. Report of the 2nd cased found in Mexican Republic. Bol Med Hosp Infant Mex 1979, 36:909-17

25. Slais J, Sterba J: Solitary liver granulomas in man caused by Capillario hepatica (Bancroft, 1983) in Czechoslovakia. Folia Parasitol (Praha) 1972, 19:373-4.

26. El Nassery SF, El Gebaly MW, El Azzouni MZ, Hammouda NA, El Shenawie S, Allan SR: Effect of mebendazole and ivermectin in experimental hepatic capillaries B: histopathological and ultrastructural studies. J Egypt Soc Parasitology 1996, 26:315-26.

27. Galvão VA: An attempt at detecting Capillaria hepatica infection in man. Rev Inst Med Trop São Paulo 1979, 21:231-236.

28. Juris P, Vilagiová I, Plachý P: The importance of files (Diptera-Brachycera) in the dissemination of helminth eggs from sewage treatment plants. $R$ Vet Med (Praha) 1995, 40:282-92.

29. Schwartzbrod J, Banas S: Parasite contamination of liquid sludge from urban wastewater treatment plants. Water Sci Technol 2003, 47:163-6.

30. Mizgajka H: Biological infection of soil in the flooded area of Wroclaw City. Waid Parazytology 1999, 45:89-93.

31. Matsuo J, Nakashio S: Prevalence of fecal contamination is sandpits in public parks in Sapporo City, Japan. Vet Parasitology 2005, 10:115-9.

doi:10.1186/1756-3305-3-11

Cite this article as: Camargo et al:: Capillariaisis (Trichurida,

Trichinellidae, Capillaria hepatica) in the Brazilian Amazon: low pathogenicity, low infectivity and a novel mode of transmission. Parasites \& Vectors 2010 3:11. 